\title{
ESCAPE WORTHINESS OF VEHICLES WITH PASSIVE BELT RESTRAINT SYSTEMS
}

\author{
Edmundo Rodarte \\ Jerry L. Purswell \\ Robert Schlegel \\ University of Oklahoma \\ Norman, OK 73072 \\ Richard F. Krenek \\ Krenek and Associates, Inc. \\ Norman, OK 73072
}

\begin{abstract}
There are a variety of conditions that can exist in the post-crash environment which make rapid escape necessary for survival or to avoid further injury. These include a post-crash fire, the vehicle going into the water, or avoiding being struck in a secondary collision. The National Highway Traffic Safety Administration (NHTSA) has defined this parameter vehicle escapeworthiness. It has been estimated in past research performed by the author for NHTSA that escapeworthiness becomes important in up to $7 \%$ of all vehicle crashes. Since escapeworthiness research was performed in the early 1970's, the advent of passive shoulder belt systems has made it necessary to again review the impact of this development on escapeworthiness. In particular, the inability of the occupants to release the passive restraint because the door cannot be opened after the crash, coupled with the inability to release the passive restraint due to its design or a lack of experience, or knowledge of how to release the passive restraint while the door is closed, creates a serious problem. Thus, the present study was performed to investigate the impact of passive restraint systems on the time required to escape from the vehicle under various conditions of available escape routes, and physical condition of the occupants. The experimental design included the variables of age, gender, escape route, level of incapacitation and type of passive restraint system. The times to effect an escape as well as the method of escaping were determined through videographic analysis of all escape trials. The findings demonstrated that the use of passive restraint systems increased the time to escape significantly, ranging from 37 to 65 percent for the respective conditions. This difference may determine whether a person survives or not after some post-crash conditions. The results have significance for the design of passive restraint systems for easy release, while at the same time not creating an incentive for some users to routinely leave the passive restraint unfastened.
\end{abstract}

\section{INTRODUCTION}

The following true example illustrates the need for post-crash escapeworthiness of vehicles. A tourist couple from Europe were driving in Miami when their rented Ford Escort was struck from behind as they stopped in front of the gates which were coming down at a railway crossing. The Escort was propelled onto the tracks as it was also spun around from the collision at the right rear. The driver of the vehicle was able to exit the vehicle and his passive shoulder belt retracted as expected. Seeing the approaching train, he quickly tried to open the passenger door to help his dazed wife exit. The door was jammed from the collision. Going back into the driver's side door, he attempted to free his wife by releasing her shoulder restraint, but could not find the emergency release near the center console. He 
then ran to flag the train which was rapidly approaching, but the train was unable to stop in time to avoid the collision. His wife was fatally injured when the Escort was struck by the train.

There are other situations where a vehicle may be involved in a collision and come to rest on a roadway where it is subject to secondary collisions or where a fire ensues after the crash. In such circumstances there is a need for the passengers to make a rapid escape or for rescuers to quickly remove injured passengers. With the advent of passive shoulder belts, there are more actions required to release both the lap belt and passive restraint shoulder belt in an escape situation. There is also the issue of whether the driver or passenger knows how and where to release the passive shoulder belt when the in-frequent need arises. From the stand-point of overall safety of the system, however, the argument can be made that perhaps the passive shoulder belt will be released and not used if the driver or passenger of the vehicle knows that it can be readily released.

The purpose of this study was to examine this issue of whether a passive shoulder belt system would add significantly to the time to escape from a vehicle in an emergency condition or to the time required to rescue an injured passenger with such a restraint.

\section{METHOD}

Experimental Design

Five independent variables were investigated in this study. They were as follows:

\section{Seat Belt Type:}

(a) non-detachable passive shoulder beit

(b) detachable passive shoulder belt

(c) standard three-point manual belt

2. Escape Routes:
(a) two doors
(b) driver's side door

(c) driver's side window

(d) two windows

3. Occupant Condition:
(a) no injuries
(b) one injury

4. Age Group:

(a) 19-29 (younger)

(b) $39-50$ (older)

5. Gender:

(a) two males in front seats

(b) two females in front seats

The injured passenger condition was simulated by using an adult size anthropometric dummy minus the legs for the passenger. The legs were removed to reduce the weight of the dummy from $70 \mathrm{~kg}$ to $54 \mathrm{~kg}$ to better correspond with the average female adult weight. The Institutional Review Board of the University of Oklahoma considered that extracting a person from the vehicle in a simulated emergency condition presented too great a risk of injury.

\section{Experimental Equipment}

A 1993 Ford Escort with four doors was used for the passive restraint vehicle. A 1985 Ford Escort was used for the three-point, continuous-loop belt system. The body styles of the two vehicles were similar, except that the 1993 Escort had a slightly larger front door opening (8597 sq cm vs. $7721 \mathrm{sq} \mathrm{cm}$ ). The Ford Escort with a passive restraint system originally had the release for the shoulder belt in the center console. In later models the release was placed at the point where the belt attaches to the track over the door.

The experimental vehicles were modified so that the experimenter could cause any door or window to be inoperable by either the driver or passenger for a given trial. Thus, there was the element of uncertainty for the driver or 
passenger after the trial started as to which escape routes would be available. This added an element of realism of the actual crash situation where the available escape exits are not likely to be known until the passengers try to escape.

The signal to start the escape trial was provided by an $80 \mathrm{dbA}$ fire alarm which sounded for three seconds. The possibility of injury while escaping from the windows was minimized by the use of eight inches of foam mattresses under each window. A video camera was used to record the motions of the subjects both inside and outside the vehicle.

\section{Subjects}

A total of 12 females and 12 males participated as subjects. They were classified into two binary dimensions, the older and younger groups and the male and female groups. The older group had an age range of $39-59$, while the younger group had an age range of 19-29. The height of the female subjects ranged from $1.47 \mathrm{~m}$ to $1.82 \mathrm{~m}(\overline{\mathrm{x}}=1.63$ $\mathrm{m})$, while the male heights ranged from $1.68 \mathrm{~m}$ to $1.96 \mathrm{~m}(\overline{\mathrm{x}}=1.81 \mathrm{~m})$. Weights of female subjects ranged from $45.5 \mathrm{~kg}$ to $72.7 \mathrm{~kg}$ $(x=61.8 \mathrm{~kg}$ ), while that of males ranged from $63.6 \mathrm{~kg}$ to $97.7 \mathrm{~kg}$ ( $\overline{\mathrm{x}}=79.5 \mathrm{~kg}$ ). All were screened for any medical conditions that would have affected their safety in performing the escape trials. The subjects were assigned to the experimental conditions in such a manner as to minimize learning. Each subject participated in only three trials, and none represented the same experimental condition. While it would have been ideal to have only one group of subjects for each condition, the assignment used represented a reasonable compromise.

\section{Procedure}

The experimental trials were conducted in the University of Oklahoma armory where the interior lighting could be controlled to a level adequate for subjects to observe the interior of the Escort while effecting an escape and sufficient for the video camera to record movements both inside and outside the vehicle.

The seat position of the Escort was inclined at 95 degrees and the seat distance from the dash was adjusted for the mid position. Subjects were instructed to buckle the manual lap belt or the three point belt after entering the vehicle. They were told that the passive shoulder belt would deploy around them after they entered. They were told that one or more of the two front doors and two front windows would be available for escape. They were not to anticipate the start signal and they must be watching the video camera at the start of the trial. They were also told that the dummy represented an injured person and that it should be treated as such. In the case of the female groups, they were told that they should release the lap and shoulder belts, but not attempt to remove the dummy as done by the male groups. In the condition where the trial was for a shoulder belt that would not release from the track, the release button was taped before the trial.

Subjects were not permitted to observe other trials in order to minimize learning effects.

\section{Criterion Measures}

The two criterion measures were the time for the first person to escape and the time for both persons to exit or for the dummy to be removed from the vehicle in the case of the male groups with an injured passenger.

\section{RESULTS}

The data was analyzed using a factorial ANOVA. Results of this analysis included the following: 
* Driver escape time was significantly $(\alpha=.05)$ affected by seat belt type, escape route, occupant condition and gender, but not by the age groups included in this study.

* Passenger escape time was significantly $(\alpha=.05)$ affected by escape route only.

* Total escape time was significantly $(\alpha=.05)$ affected by seat belt type, escape route, occupant condition and gender, but not by the age groups included in this study.

A Neuman-Keuls range test on driver, passenger and total mean escape times indicated the following:

* The three point manual belt permitted significantly $(\alpha=.05)$ faster escape times than either the passive detachable or passive nondetachable restraint systems (See Figure 1).

* As expected, window escape routes produce significantly longer escape times than door escape routes (See Figure 2).

* An injured person significantly $(\alpha=.05)$ increased total escape time (by over 100\%) over the situation where neither occupant was injured. Driver escape times were significantly $(\alpha=05)$ higher where there was an injury to the passenger (See Figure 3).

* Driver and total escape times for male subjects was significantly $(\alpha=.05)$ shorter than for female subjects (See Figure 4).

\section{DISCUSSION}

This study has demonstrated that the added safety advantage of a passive shoulder belt restraint system can add significantly to the time to escape from a vehicle under certain emergency conditions. Even when the belt was detachable, escape times did not differ significantly from non-detachable shoulder belts because of the difficulty that subjects had in understanding the method and finding the location to release the shoulder belt. Subjects were observed attempting to find the release button near the point that they had released the lap belt, rather than near the track for the belt.

This observation may indicate the need for manufacturers to carefully consider the needs for instructions and labels about how to operate the release mechanism for the shoulder belt. At a more basic level, however, standardization of both passive restraint release location and release mechanism operation among automobile manufacturers should be considered. This would be important for drivers and passengers who are not familiar with the vehicle as is the case when renting an automobile on a short term basis.

One aspect to consider in designing the passive belt release mechanism is that a passive restraint that is easy to release may encourage some users to release the passive restraint and not use it.

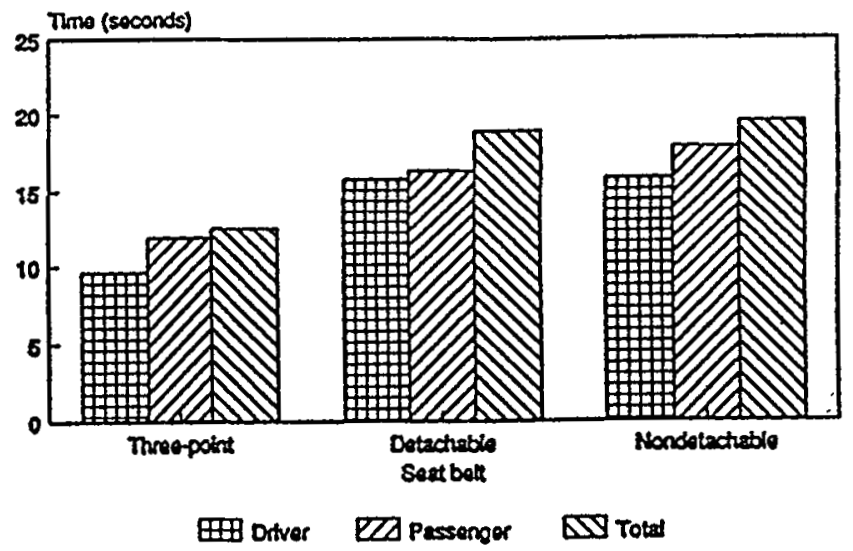

Figure 1. Driver, passenger and total escape time as a function of seat belt type (male and female). 


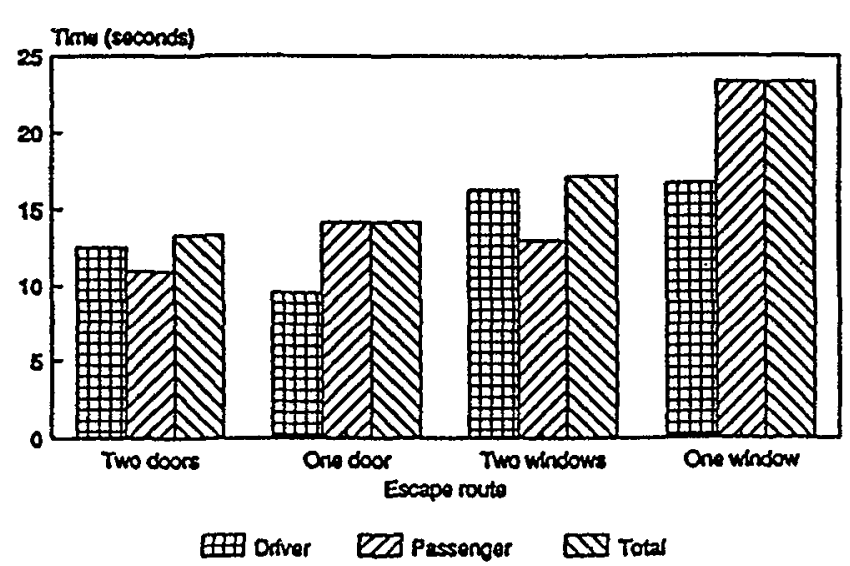

Figure 2. Driver, passenger and total escape time as a function of escape route (male and female).

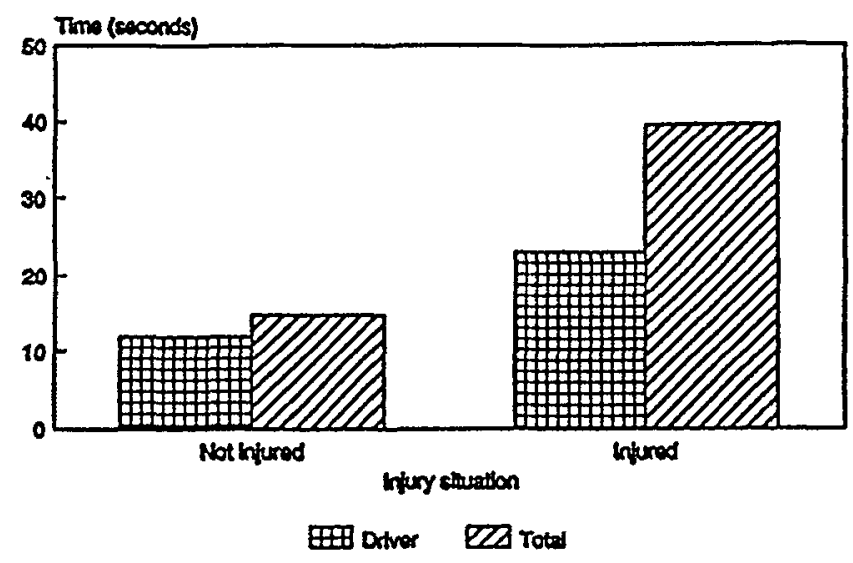

Figure 3. Driver and total escape time as a function of injury situation (male subjects).

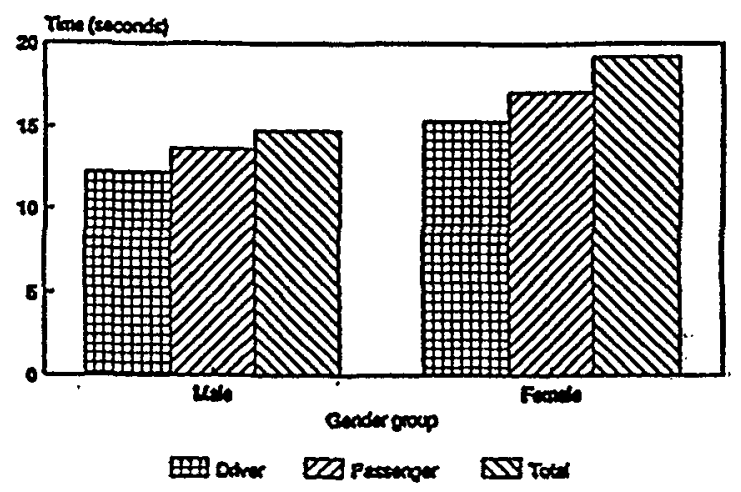

Figure 4. Driver, passenger and total escape time as a function of gender group (male and female).

\section{REFERENCES}

Congress of the United States, Technology and Handicapped People. Background Paper \#1: Mandatory Passive Restraint Systems in Automobiles: Issues and Evidence, November 1982.

Department of Transportation, Passive Restraints for Automobile Occupants - A Closer Look, July 1979.

Kurylko, D., Escort Passenger Decaptitated by Motorized Shoulder beit. Automotive News, June 1991.

Miami Police, Accident report for Miko accident, 1990.

University of Oklahoma Research Institute, Escapeworthiness of Vehicles for Occupancy Survivals, Report No. 1770FR-1-1, July 1972.

Williams A., J. Wells, A. Lund, N. Teed, Seat Belt Use in Cars with Automatic Belts. Insurance Institute for Highway Safety, August, 1990. 